\title{
Identification of candidate biomarkers and pathways associated with SCLC by bioinformatics analysis
}

\author{
PUSHUAI WEN $^{1,2}$, TUNGAMIRAI CHIDANGURO ${ }^{1}$, ZHUO SHI $^{3}$, HUANYU GU $^{1}$, \\ NAN WANG ${ }^{1}$, TONGMEI WANG ${ }^{1}$, YUHONG $\mathrm{LI}^{4}$ and JING GAO ${ }^{4}$ \\ ${ }^{1}$ Department of Pathophysiology; ${ }^{2}$ Biological Anthropology Institute; \\ ${ }^{3}$ Department of Anatomy, Jinzhou Medical University; ${ }^{4}$ Department of Ultrasonography, \\ The First Affiliated Hospital of Jinzhou Medical University, Jinzhou, Liaoning 121001, P.R. China
}

Received December 6, 2017; Accepted April 23, 2018

DOI: $10.3892 / \mathrm{mmr} .2018 .9095$

\begin{abstract}
Small cell lung cancer (SCLC) is one of the highly malignant tumors and a serious threat to human health. The aim of the present study was to explore the underlying molecular mechanisms of SCLC. mRNA microarray datasets GSE6044 and GSE11969 were downloaded from Gene Expression Omnibus database, and the differentially expressed genes (DEGs) between normal lung and SCLC samples were screened using GEO2R tool. Functional and pathway enrichment analyses were performed for common DEGs using the DAVID database, and the protein-protein interaction (PPI) network of common DEGs was constructed by the STRING database and visualized with Cytoscape software. In addition, the hub genes in the network and module analysis of the PPI network were performed using CentiScaPe and plugin Molecular Complex Detection. Finally, the mRNA expression levels of hub genes were validated in the Oncomine database. A total of 150 common DEGs with absolute fold-change $>0.5$, including 66 significantly downregulated DEGs and 84 upregulated DEGs were obtained. The Gene Ontology term enrichment analysis suggested that common upregulated DEGs were primarily enriched in biological processes (BPs), including 'cell cycle', 'cell cycle phase', 'M phase', 'cell cycle process' and 'DNA metabolic process'. The common downregulated genes were significantly enriched in BPs, including 'response to wounding', 'positive regulation of immune system process', 'immune response', 'acute inflammatory response' and 'inflammatory response'. Kyoto Encyclopedia of Genes and Genomes pathway analysis identified that the
\end{abstract}

Correspondence to: Professor Yuhong Li or Dr Jing Gao, Department of Ultrasonography, The First Affiliated Hospital of Jinzhou Medical University, 2, Section V Renmin Street, Jinzhou, Liaoning 121001, P.R. China

E-mail: yuhong_jiahui@163.com

E-mail: gaojinggg@163.com

Key words: lung cancer, small cell lung cancer, differentially expressed genes, bioinformatics analysis, microarray common downregulated DEGs were primarily enriched in the 'complement and coagulation cascades' signaling pathway; the common upregulated DEGs were mainly enriched in 'cell cycle', 'DNA replication', 'oocyte meiosis' and the 'mismatch repair' signaling pathways. From the PPI network, the top 10 hub genes in SCLC were selected, including topoisomerase II $\alpha$, proliferating cell nuclear antigen, replication factor $\mathrm{C}$ subunit 4, checkpoint kinase 1, thymidylate synthase, minichromosome maintenance protein (MCM) 2, cell division cycle (CDC) 20, cyclin dependent kinase inhibitor 3, MCM3 and CDC6, the mRNA levels of which are upregulated in Oncomine SCLC datasets with the exception of MCM2. Furthermore, the genes in the significant module were enriched in 'cell cycle', 'DNA replication' and 'oocyte meiosis' signaling pathways. Therefore, the present study can shed new light on the understanding of molecular mechanisms of SCLC and may provide molecular targets and diagnostic biomarkers for the treatment and early diagnosis of SCLC.

\section{Introduction}

Lung cancer is one of the highly malignant tumors and a serious threat to human health. The incidence and mortality rates of lung cancer are the highest of any type of cancer, particularly in China (1). Despite the advances and developments in the treatments for lung cancer, the 5-year survival rate of patients with lung cancer remains only $16 \%$, and the 5 -year recurrence rate is $50 \%$ (2). Based on differences in presentation and behavior, primary lung cancer is divided into two main histological subtypes: Small cell lung cancer (SCLC) and non-SCLC (NSCLC) (3). Although SCLC only accounts for $15 \%$ of lung cancers, it is an aggressive high-grade neuroendocrine tumor associated with early and widespread metastasis and development of resistance to chemotherapy, which contribute to the extremely poor prognosis of patients with the disease $(4,5)$. Previously, several common genetic alterations in SCLC have been identified, including functional inactivation of the tumor-suppressor genes tumor protein p53 and RB transcriptional corepressor 1, as well as amplification of genes encoding Myc family members, enhancer of zeste homolog 2 (EZH2) involved in chromatin remodeling, epidermal growth factor receptor and B-cell lymphoma 2 
receptor tyrosine kinases, their downstream effectors, and Notch family proteins (4,6-10). These may provide opportunities for classification and therapeutic intervention, including poly (ADP-ribose) polymerase (PARP) inhibitors, EZH2 inhibition and Wee1 inhibitor (11-15). Therefore, more effort needs to be invested towards the investigation and understanding of molecular mechanisms in development and progression of SCLC, which are crucial for the development of more effective diagnostic and therapeutic strategies.

Recently, the gene expression profile chip, a high-throughput and effective technique, has been widely used in a variety of disease research fields to reveal the association between disease and genes, and provide the valuable clues for the pathogenesis of the diseases, including lung cancer (16-18). Kikuchi et al (19) identified several genes, which may be used for the prediction of lymph-node metastasis and sensitivity to anti-cancer drugs. Yanaihara et al (20) identified that high hsa-mir-155 and low hsa-let-7a-2 expression levels correlated with poor survival, which indicated that micro (mi)RNA expression profiles are diagnostic and prognostic markers of lung cancer. Furthermore lung adenocarcinoma has been defined to represent distinct molecular subclasses according to the miRNA expression profiling data (21). Although the cellular and molecular genetic alterations underlying SCLC have become better understood, the molecular mechanisms of SCLC have yet to be fully elucidated.

In order to investigate the molecular mechanisms of SCLC, the present study re-analyzed the gene expression profiles of GSE6044 and GSE11969 $(22,23)$ and identified the differentially expressed genes (DEGs) between normal lung tissue and SCLC. Subsequently, comprehensive bioinformatics analysis was used for biological process (BP) annotation and biological pathway enrichment analysis. The protein-protein interaction (PPI) network of common DEGs was constructed and analysis performed on the hub genes and modules of the PPI network. Therefore, the findings of the present study may provide further understanding of SCLC development and lead to an improved diagnosis of SCLC.

\section{Materials and methods}

Expression profile microarray. Data was downloaded from the Gene Expression Omnibus (GEO), a public repository for data storage (www.ncbi.nlm.nih.gov/geo) (24). A total of 2 mRNA expression datasets of SCLC, GSE6044 and GSE11969, were included in the present study $(22,23)$. The dataset GSE6044 based on GPL201 (HG-Focus) Affymetrix Human HG-Focus Target Array platform (Affymetrix; Thermo Fisher Scientific, Inc., Waltham, MA, USA), included 5 normal lung and 9 SCLC samples; the dataset GSE11969 also included 5 normal lung and 9 SCLC samples based on the platform of GPL7015 Agilent Homo sapiens 21.6K custom array (Agilent Technologies, Inc., Santa Clara, CA, USA).

Identification of DEGs. The DEGs between normal lung and SCLC samples were screened by an interactive web tool, GEO2R (www.ncbi.nlm.nih.gov/geo/geo2r) (25). The adjusted $\mathrm{P}$-value using the Benjamini and Hochberg false discovery rate (FDR) method was applied to correct for the occurrence of false positive results. The adjusted $\mathrm{P}$-value $<0.05$ and $\mid \log \mathrm{FCl}>0.5$ were set as the cut-off criteria. The heat map of DEGs was generated using the gplots package for $\mathrm{R}$ (http://cran.r-project.org/web/packages/gplots/; version 3.4.3).

Gene ontology (GO) terms and kyoto encyclopedia of genes and genomes (KEGG) pathway enrichment analysis. The Database for Annotation, Visualization and Integrated Discovery (DAVID, david.abcc.ncifcrf.gov) is an online program that provides a comprehensive set of functional annotation tools for researchers to understand the biological meaning behind numerous genes (26). GO, including molecular function, biological processes (BP) and cellular components and KEGG pathway enrichment analyses were performed for identified DEGs using the DAVID database (version 6.7). FDR $<0.05$ was used as a cutoff for significance.

Construction of PPI, hub gene identification and module analysis of the PPI network. The Search Tool for the Retrieval of Interacting Genes (STRING) database (version 10.5; http://string-db.org/), is an online tool designed to explore and analyze PPI information. To evaluate the interactive associations among common DEGs, the common DEGs were mapped using STRING, and interactions with a combined score $>0.4$ were selected. Then, the PPI network was constructed and visualized using Cytoscape software (version 3.5.1; www.cytoscape.org). In order to identify key elements in BP, the hub genes in the network defined as possessing a connective degree $>10$, were identified using CentiScaPe v2.0 plugin for Cytoscape (version 3.5.1; www.cytoscape.org). The topological properties of the PPI network, including average clustering coefficients, topological coefficients and shortest path lengths, were investigated using a Network Analyzer (version 2.7; med.bioinf.mpi-inf.mpg.de/netanalyzer/download.php) and Cytoscape (version 3.5.1; www.cytoscape.org) plugin app (27). Finally, module analysis was carried out by the plug-in Molecular Complex Detection (MCODE; version 1.5.1) with cut-off criterion: MCODE score $>4$ and number $>5$.

Validation of the expression of hub genes in oncomine database. Oncomine (www.oncomine.org; Ion Torrent; Thermo Fisher Scientific, Inc.) is an online cancer microarray database to facilitate the discovery of genome-wide expression analyses (28). To validate the expression level of hub genes in SCLC, Garber et al (29) and Bhattacharjee et al (21) lung cancer gene expression data in the Oncomine database were searched for expression levels of hub genes in the network with a P-value $<0.05$. Thresholds for fold-change and gene rank were set to 'all', whereas the data type was restricted to mRNA. Statistical significance was provided by Oncomine in the form of a Student's t-test.

\section{Results}

Identification of DEGs. Gene expression datasets GSE6044 and GSE11969 were downloaded from GEO datasets. GEO2R was applied to screen DEGs between normal lung tissue and SCLC samples. A total of 1,025 and 1,006 DEGs were identified from GSE6044 and GSE11969 datasets, respectively (Fig. 1A and B). Among them, 481 downregulated genes and 544 upregulated genes in the GSE6044 dataset, and 
Table I. The 150 common DEGs in the GSE6044 dataset.

A, Downregulated DEGs

\begin{tabular}{|c|c|c|c|c|c|}
\hline Gene symbol & Log fold-change & Adjusted P-value & Gene symbol & Log fold-change & Adjusted P-value \\
\hline CYP4B1 & -4.26 & $3.14 \times 10^{-4}$ & LYN & -1.04 & $3.06 \times 10^{-2}$ \\
\hline CX3CL1 & -4.23 & $7.58 \times 10^{-4}$ & C6 & -1.02 & $4.37 \times 10^{-3}$ \\
\hline FBLN5 & -3.26 & $1.22 \times 10^{-3}$ & HNMT & -1.01 & $4.43 \times 10^{-3}$ \\
\hline SCGB1A1 & -3.16 & $5.10 \times 10^{-3}$ & PRNP & -1.01 & $2.72 \times 10^{-2}$ \\
\hline AQP3 & -2.76 & $3.70 \times 10^{-2}$ & CCND1 & -0.98 & $1.31 \times 10^{-2}$ \\
\hline ADH1C & -2.75 & $9.50 \times 10^{-4}$ & TCF21 & -0.96 & $6.18 \times 10^{-3}$ \\
\hline CSTA & -2.60 & $1.87 \times 10^{-2}$ & CST3 & -0.95 & $2.20 \times 10^{-3}$ \\
\hline ALDH1A1 & -2.49 & $2.66 \times 10^{-3}$ & CNN2 & -0.95 & $1.07 \times 10^{-2}$ \\
\hline $\mathrm{CFH}$ & -2.32 & $1.49 \times 10^{-3}$ & NEDD9 & -0.91 & $1.29 \times 10^{-2}$ \\
\hline CLU & -2.08 & $1.28 \times 10^{-3}$ & IL4R & -0.91 & $3.37 \times 10^{-2}$ \\
\hline ADH1B & -2.07 & $3.39 \times 10^{-3}$ & THBD & -0.90 & $4.91 \times 10^{-2}$ \\
\hline PTGDS & -1.94 & $5.01 \times 10^{-3}$ & EPHA2 & -0.87 & $2.92 \times 10^{-2}$ \\
\hline PROS1 & -1.87 & $1.93 \times 10^{-3}$ & ZFP36L2 & -0.86 & $4.88 \times 10^{-2}$ \\
\hline TGFBR3 & -1.80 & $7.75 \times 10^{-3}$ & SLC16A5 & -0.83 & $2.59 \times 10^{-3}$ \\
\hline ANXA11 & -1.73 & $4.77 \times 10^{-3}$ & STAT6 & -0.83 & $2.09 \times 10^{-2}$ \\
\hline LAMB3 & -1.73 & $4.78 \times 10^{-3}$ & SP110 & -0.69 & $3.10 \times 10^{-2}$ \\
\hline DMBT1 & -1.72 & $4.59 \times 10^{-2}$ & TLR2 & -0.63 & $4.12 \times 10^{-2}$ \\
\hline F13A1 & -1.72 & $2.19 \times 10^{-2}$ & CFTR & -0.61 & $2.77 \times 10^{-2}$ \\
\hline FLRT3 & -1.72 & $4.58 \times 10^{-2}$ & VAV1 & -0.53 & $3.77 \times 10^{-3}$ \\
\hline RRAD & -1.70 & $1.88 \times 10^{-3}$ & & & \\
\hline TACSTD2 & -1.67 & $2.54 \times 10^{-2}$ & \multirow{2}{*}{\multicolumn{3}{|c|}{ B, Upregulated DEGs }} \\
\hline $\mathrm{C} 3$ & -1.66 & $1.03 \times 10^{-2}$ & & & \\
\hline PLK2 & -1.66 & $5.62 \times 10^{-3}$ & Gene symbol & Log fold-change & Adjusted P-value \\
\hline EPAS1 & -1.65 & $6.31 \times 10^{-3}$ & & & \\
\hline PZP & -1.57 & $2.83 \times 10^{-3}$ & $\mathrm{KCNH} 2$ & 0.52 & $2.49 \times 10^{-2}$ \\
\hline CXCL1 & -1.55 & $4.10 \times 10^{-3}$ & RAD54L & 0.52 & $2.49 \times 10^{-2}$ \\
\hline CAST & -1.49 & $3.13 \times 10^{-3}$ & CBX5 & 0.59 & $1.01 \times 10^{-2}$ \\
\hline ANXA1 & -1.42 & $3.49 \times 10^{-2}$ & DDC & 0.61 & $3.27 \times 10^{-2}$ \\
\hline RNASE4 & -1.39 & $7.39 \times 10^{-4}$ & RECQL4 & 0.62 & $5.10 \times 10^{-3}$ \\
\hline CTSH & -1.33 & $7.49 \times 10^{-4}$ & CHEK1 & 0.64 & $4.79 \times 10^{-2}$ \\
\hline CD9 & -1.31 & $2.85 \times 10^{-2}$ & ENC1 & 0.64 & $2.00 \times 10^{-2}$ \\
\hline ADRB2 & -1.30 & $2.62 \times 10^{-2}$ & SOX11 & 0.67 & $1.92 \times 10^{-2}$ \\
\hline PTGER4 & -1.26 & $1.13 \times 10^{-2}$ & BIRC5 & 0.69 & $5.60 \times 10^{-3}$ \\
\hline FOLR1 & -1.22 & $5.56 \times 10^{-3}$ & CKS1B & 0.69 & $1.87 \times 10^{-2}$ \\
\hline BAG3 & -1.21 & $1.50 \times 10^{-2}$ & GNG4 & 0.70 & $2.24 \times 10^{-2}$ \\
\hline CAPN2 & -1.21 & $5.21 \times 10^{-3}$ & EZH2 & 0.71 & $9.45 \times 10^{-4}$ \\
\hline CD81 & -1.21 & $2.21 \times 10^{-2}$ & FANCA & 0.71 & $9.45 \times 10^{-4}$ \\
\hline SERPINA1 & -1.21 & $2.26 \times 10^{-2}$ & STMN1 & 0.71 & $9.45 \times 10^{-4}$ \\
\hline VAMP8 & -1.21 & $1.51 \times 10^{-2}$ & EXO1 & 0.71 & $7.39 \times 10^{-3}$ \\
\hline GPX3 & -1.19 & $1.45 \times 10^{-2}$ & GRP & 0.71 & $7.39 \times 10^{-3}$ \\
\hline MYO5C & -1.19 & $1.46 \times 10^{-2}$ & CDKN3 & 0.73 & $7.18 \times 10^{-3}$ \\
\hline PCSK5 & -1.19 & $2.10 \times 10^{-3}$ & FKBP3 & 0.78 & $7.93 \times 10^{-3}$ \\
\hline HLA-E & -1.18 & $5.52 \times 10^{-3}$ & NRTN & 0.79 & $2.86 \times 10^{-2}$ \\
\hline FBLN1 & -1.12 & $1.24 \times 10^{-2}$ & ASCL1 & 0.81 & $8.66 \times 10^{-3}$ \\
\hline $\mathrm{A} 2 \mathrm{M}$ & -1.11 & $1.67 \times 10^{-2}$ & CENPF & 0.81 & $5.56 \times 10^{-3}$ \\
\hline TGM2 & -1.07 & $7.86 \times 10^{-3}$ & PCSK1 & 0.83 & $5.62 \times 10^{-3}$ \\
\hline TGFBR2 & -1.06 & $1.98 \times 10^{-2}$ & MYBL2 & 0.86 & $2.27 \times 10^{-2}$ \\
\hline PXMP2 & 0.50 & $4.38 \times 10^{-2}$ & TRIM36 & 0.86 & $2.26 \times 10^{-2}$ \\
\hline NOL4 & 0.51 & $4.98 \times 10^{-3}$ & MSH6 & 0.86 & $5.21 \times 10^{-3}$ \\
\hline MKI67 & 0.52 & $4.11 \times 10^{-2}$ & TPD52 & 0.89 & $1.64 \times 10^{-2}$ \\
\hline
\end{tabular}

Table I. Continued.

A, Downregulated DEGs

Upregulated DEG 
Table I. Continued.

B, Upregulated DEGs

\begin{tabular}{|c|c|c|}
\hline Gene symbol & Log fold-change & Adjusted P-value \\
\hline CDC7 & 0.90 & $1.98 \times 10^{-3}$ \\
\hline PSIP1 & 0.90 & $1.98 \times 10^{-3}$ \\
\hline PRDX2 & 0.91 & $2.19 \times 10^{-2}$ \\
\hline FZD3 & 0.91 & $4.66 \times 10^{-3}$ \\
\hline HDAC2 & 0.94 & $3.14 \times 10^{-4}$ \\
\hline MCM6 & 0.94 & $3.14 \times 10^{-4}$ \\
\hline MEST & 0.94 & $3.14 \times 10^{-4}$ \\
\hline SOX4 & 0.94 & $3.14 \times 10^{-4}$ \\
\hline TOP2A & 0.94 & $3.14 \times 10^{-4}$ \\
\hline TYMS & 0.94 & $3.14 \times 10^{-4}$ \\
\hline CDC20 & 0.95 & $1.88 \times 10^{-3}$ \\
\hline LHX2 & 0.97 & $2.16 \times 10^{-2}$ \\
\hline HPRT1 & 0.99 & $9.71 \times 10^{-3}$ \\
\hline PARP1 & 0.99 & $9.71 \times 10^{-3}$ \\
\hline CDC6 & 1.02 & $2.97 \times 10^{-3}$ \\
\hline PCNA & 1.08 & $1.84 \times 10^{-3}$ \\
\hline NELL1 & 1.09 & $1.92 \times 10^{-2}$ \\
\hline SHMT2 & 1.11 & $9.89 \times 10^{-3}$ \\
\hline FANCG & 1.19 & $1.62 \times 10^{-3}$ \\
\hline TTK & 1.19 & $1.62 \times 10^{-3}$ \\
\hline BUB1 & 1.20 & $2.72 \times 10^{-3}$ \\
\hline PAFAH1B3 & 1.23 & $2.62 \times 10^{-3}$ \\
\hline SPAG5 & 1.25 & $4.19 \times 10^{-3}$ \\
\hline CELSR3 & 1.26 & $2.51 \times 10^{-3}$ \\
\hline ITGB3BP & 1.27 & $1.56 \times 10^{-2}$ \\
\hline DTYMK & 1.29 & $1.77 \times 10^{-3}$ \\
\hline DLK1 & 1.31 & $3.32 \times 10^{-3}$ \\
\hline DEK & 1.33 & $6.17 \times 10^{-4}$ \\
\hline RFC5 & 1.39 & $1.21 \times 10^{-3}$ \\
\hline KIF11 & 1.41 & $3.53 \times 10^{-3}$ \\
\hline NEK2 & 1.41 & $3.09 \times 10^{-3}$ \\
\hline UNG & 1.48 & $1.28 \times 10^{-3}$ \\
\hline MCM3 & 1.52 & $1.39 \times 10^{-3}$ \\
\hline CAMK2B & 1.53 & $2.43 \times 10^{-2}$ \\
\hline TIMELESS & 1.60 & $2.07 \times 10^{-3}$ \\
\hline USP1 & 1.60 & $6.35 \times 10^{-4}$ \\
\hline CCNB2 & 1.61 & $3.13 \times 10^{-3}$ \\
\hline FBXO5 & 1.62 & $1.46 \times 10^{-3}$ \\
\hline ZWINT & 1.67 & $7.39 \times 10^{-4}$ \\
\hline GMNN & 1.79 & $1.52 \times 10^{-3}$ \\
\hline $\mathrm{COCH}$ & 1.83 & $1.45 \times 10^{-3}$ \\
\hline PTTG1 & 1.85 & $7.46 \times 10^{-3}$ \\
\hline MCM2 & 1.90 & $4.17 \times 10^{-3}$ \\
\hline MAD2L1 & 1.98 & $2.59 \times 10^{-3}$ \\
\hline CCNE2 & 1.99 & $7.62 \times 10^{-3}$ \\
\hline RACGAP1 & 2.00 & $1.77 \times 10^{-3}$ \\
\hline CHGB & 2.04 & $3.42 \times 10^{-3}$ \\
\hline ASNS & 2.16 & $2.61 \times 10^{-3}$ \\
\hline RRM2 & 2.40 & $2.24 \times 10^{-3}$ \\
\hline RFC4 & 2.52 & $3.41 \times 10^{-4}$ \\
\hline
\end{tabular}

Table I. Continued.

B, Upregulated DEGs

\begin{tabular}{lcc}
\hline Gene symbol & Log fold-change & Adjusted P-value \\
\hline CKS2 & 2.60 & $1.09 \times 10^{-3}$ \\
RBP1 & 2.75 & $5.41 \times 10^{-3}$ \\
UCHL1 & 3.08 & $3.37 \times 10^{-4}$ \\
ISL1 & 3.17 & $4.91 \times 10^{-3}$ \\
INSM1 & 3.65 & $5.28 \times 10^{-3}$ \\
\hline
\end{tabular}

DEGs, differentially expressed genes.

706 downregulated genes and 300 upregulated genes in the GSE11969 dataset, were identified. In addition, 150 common DEGs were obtained (Tables I and II), comprising 66 co-downregulated genes and 84 co-upregulated genes (Fig. 1C and D).

Biological classification and pathway enrichment analysis of common DEGs. To gain an understanding of the GO categories of common DEGs, all common DEGs were uploaded to the DAVID database. The downregulated DEGs were significantly enriched in BPs, including 'response to wounding', 'positive regulation of immune system process', 'immune response', 'acute inflammatory response' and 'inflammatory response'; the upregulated genes were significantly enriched in 'cell cycle', 'cell cycle phase', 'M phase', 'cell cycle process' and 'DNA metabolic process'. For cellular component, the downregulated DEGs were significantly enriched in the 'extracellular region', 'extracellular region part', 'extracellular space', 'platelet $\alpha$-granule', and 'cytoplasmic vesicle part'; and the upregulated DEGs were significantly enriched in 'chromosome', 'chromosomal part', 'nuclear lumen', 'spindle' and 'intracellular organelle lumen'. In addition, MF analysis also indicated that the downregulated DEGs were significantly enriched in 'enzyme inhibitor activity', 'endopeptidase inhibitor activity' and 'peptidase inhibitor activity' (Fig. 2A and B).

Following KEGG pathway enrichment analysis, the common downregulated DEGs were identified to be primarily enriched in the 'complement and coagulation cascades' signaling pathways; the common upregulated DEGs were mainly enriched in 'cell cycle', 'DNA replication', 'oocyte meiosis' and 'mismatch repair' signaling pathways (Table III). Therefore, these significantly enriched GO terms and pathways could aid further understanding of the roles of these DEGs, involved in the occurrence and development of SCLC.

Construction of PPI network and module analysis. PPI network of common DEGs was constructed using the STRING online database and Cytoscape software (Fig. 3). A total of 123 DEGs (50 downregulated and 73 upregulated) of the 150 commonly altered DEGs were filtered into the DEGs PPI network complex, containing 123 nodes and 869 edges, and 27 of the 150 DEGs fell outside the DEGs PPI network (Fig. 3A). Then, the hub genes in the networks with a connectivity degree 
Table II. The 150 common DEGs in the GSE11969 dataset.

A, Downregulated DEGs

\begin{tabular}{|c|c|c|c|c|c|}
\hline \multicolumn{3}{|c|}{ A, Downregulated DEGs } & \multicolumn{3}{|c|}{ A, Downregulated DEGs } \\
\hline Gene symbol & Log fold-change & Adjusted P-value & Gene symbol & Log fold-change & Adjusted P-value \\
\hline TGFBR2 & -1.19 & $3.30 \times 10^{-4}$ & C6 & -0.66 & $1.32 \times 10^{-4}$ \\
\hline CFTR & -1.16 & $1.03 \times 10^{-3}$ & FOLR1 & -0.65 & $9.53 \times 10^{-4}$ \\
\hline CXCL1 & -1.14 & $5.16 \times 10^{-4}$ & PLK2 & -0.65 & $1.92 \times 10^{-4}$ \\
\hline TGM2 & -1.11 & $4.73 \times 10^{-5}$ & HNMT & -0.63 & $1.23 \times 10^{-2}$ \\
\hline THBD & -1.11 & $4.73 \times 10^{-5}$ & MYO5C & -0.61 & $1.28 \times 10^{-2}$ \\
\hline EPAS1 & -1.10 & $4.13 \times 10^{-4}$ & CAST & -0.61 & $1.05 \times 10^{-2}$ \\
\hline AQP3 & -1.10 & $1.00 \times 10^{-5}$ & PTGDS & -0.61 & $4.53 \times 10^{-3}$ \\
\hline CD9 & -1.07 & $3.03 \times 10^{-3}$ & ANXA11 & -0.59 & $2.59 \times 10^{-2}$ \\
\hline ALDH1A1 & -1.03 & $4.22 \times 10^{-3}$ & CCND1 & -0.58 & $3.88 \times 10^{-5}$ \\
\hline RRAD & -1.01 & $1.52 \times 10^{-4}$ & EPHA2 & -0.58 & $3.88 \times 10^{-5}$ \\
\hline NEDD9 & -0.99 & $3.32 \times 10^{-4}$ & SERPINA1 & -0.58 & $5.84 \times 10^{-4}$ \\
\hline CX3CL1 & -0.98 & $6.32 \times 10^{-5}$ & PRNP & -0.57 & $4.65 \times 10^{-2}$ \\
\hline ANXA1 & -0.97 & $4.15 \times 10^{-4}$ & VAMP8 & -0.56 & $5.03 \times 10^{-3}$ \\
\hline CNN2 & -0.95 & $3.65 \times 10^{-4}$ & $\mathrm{ADH} 1 \mathrm{C}$ & -0.54 & $1.74 \times 10^{-3}$ \\
\hline SLC16A5 & -0.95 & $1.53 \times 10^{-4}$ & CD81 & -0.52 & $3.13 \times 10^{-3}$ \\
\hline LAMB3 & -0.94 & $2.82 \times 10^{-4}$ & IL4R & -0.51 & $3.98 \times 10^{-4}$ \\
\hline PROS1 & -0.93 & $1.49 \times 10^{-3}$ & 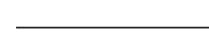 & & \\
\hline FBLN1 & -0.92 & $8.81 \times 10^{-4}$ & \multirow{2}{*}{\multicolumn{3}{|c|}{ B, Upregulated DEGs }} \\
\hline SP110 & -0.89 & $1.36 \times 10^{-2}$ & & & \\
\hline TGFBR3 & -0.88 & $7.00 \times 10^{-5}$ & Gene symbol & Log fold-change & Adjusted P-value \\
\hline RNASE4 & -0.87 & $1.76 \times 10^{-4}$ & & & \\
\hline DMBT1 & -0.86 & $6.02 \times 10^{-3}$ & $\mathrm{CCNB} 2$ & 0.50 & $1.59 \times 10^{-4}$ \\
\hline CSTA & -0.85 & $5.07 \times 10^{-3}$ & DDC & 0.50 & $1.59 \times 10^{-4}$ \\
\hline GPX3 & -0.85 & $1.10 \times 10^{-3}$ & HPRT1 & 0.50 & $1.59 \times 10^{-4}$ \\
\hline CTSH & -0.85 & $3.15 \times 10^{-3}$ & CDC20 & 0.50 & $3.39 \times 10^{-4}$ \\
\hline PTGER4 & -0.85 & $3.15 \times 10^{-3}$ & PARP1 & 0.51 & $3.92 \times 10^{-3}$ \\
\hline VAV1 & -0.84 & $8.80 \times 10^{-3}$ & FANCG & 0.51 & $3.74 \times 10^{-4}$ \\
\hline TCF21 & -0.83 & $4.99 \times 10^{-4}$ & PSIP1 & 0.51 & $3.74 \times 10^{-4}$ \\
\hline F13A1 & -0.83 & $1.22 \times 10^{-3}$ & ENC1 & 0.51 & $4.43 \times 10^{-2}$ \\
\hline TACSTD2 & -0.83 & $5.82 \times 10^{-4}$ & DEK & 0.52 & $2.91 \times 10^{-3}$ \\
\hline CST3 & -0.83 & $2.69 \times 10^{-2}$ & FZD3 & 0.52 & $6.44 \times 10^{-3}$ \\
\hline STAT6 & -0.83 & $1.02 \times 10^{-2}$ & ZWINT & 0.52 & $2.34 \times 10^{-4}$ \\
\hline ADH1B & -0.81 & $3.64 \times 10^{-3}$ & UNG & 0.52 & $3.02 \times 10^{-4}$ \\
\hline ZFP36L2 & -0.81 & $6.86 \times 10^{-4}$ & CDC7 & 0.53 & $3.98 \times 10^{-5}$ \\
\hline PZP & -0.81 & $5.75 \times 10^{-3}$ & MCM3 & 0.53 & $8.82 \times 10^{-3}$ \\
\hline $\mathrm{C} 3$ & -0.80 & $2.70 \times 10^{-2}$ & CHEK1 & 0.53 & $5.88 \times 10^{-3}$ \\
\hline CLU & -0.76 & $4.60 \times 10^{-2}$ & NRTN & 0.53 & $1.43 \times 10^{-3}$ \\
\hline CYP4B1 & -0.75 & $3.74 \times 10^{-3}$ & RBP1 & 0.53 & $5.99 \times 10^{-4}$ \\
\hline SCGB1A1 & -0.75 & $5.88 \times 10^{-3}$ & MSH6 & 0.53 & $2.16 \times 10^{-4}$ \\
\hline FLRT3 & -0.74 & $3.15 \times 10^{-2}$ & DTYMK & 0.54 & $6.60 \times 10^{-5}$ \\
\hline PCSK5 & -0.74 & $2.91 \times 10^{-3}$ & MCM2 & 0.55 & $4.74 \times 10^{-4}$ \\
\hline $\mathrm{CFH}$ & -0.72 & $2.45 \times 10^{-2}$ & CHGB & 0.56 & $3.30 \times 10^{-4}$ \\
\hline LYN & -0.72 & $1.19 \times 10^{-2}$ & EXO1 & 0.56 & $3.30 \times 10^{-4}$ \\
\hline ADRB2 & -0.71 & $6.46 \times 10^{-5}$ & CELSR3 & 0.56 & $8.00 \times 10^{-4}$ \\
\hline HLA-E & -0.71 & $9.33 \times 10^{-3}$ & CDKN3 & 0.56 & $7.01 \times 10^{-3}$ \\
\hline CAPN2 & -0.70 & $8.30 \times 10^{-3}$ & SHMT2 & 0.56 & $1.85 \times 10^{-4}$ \\
\hline BAG3 & -0.69 & $1.44 \times 10^{-3}$ & TRIM36 & 0.56 & $1.58 \times 10^{-3}$ \\
\hline TLR2 & -0.69 & $1.15 \times 10^{-3}$ & BUB1 & 0.56 & $1.23 \times 10^{-3}$ \\
\hline FBLN5 & -0.69 & $3.74 \times 10^{-4}$ & CDC6 & 0.56 & $4.94 \times 10^{-5}$ \\
\hline $\mathrm{A} 2 \mathrm{M}$ & -0.66 & $2.23 \times 10^{-2}$ & USP1 & 0.57 & $5.25 \times 10^{-4}$ \\
\hline
\end{tabular}

Table II. Continued.

Upregulated DEG 
Table II. Continued.

B, Upregulated DEGs

\begin{tabular}{|c|c|c|}
\hline Gene symbol & Log fold-change & Adjusted P-value \\
\hline PXMP2 & 0.57 & $3.87 \times 10^{-5}$ \\
\hline RACGAP1 & 0.57 & $3.87 \times 10^{-5}$ \\
\hline FKBP3 & 0.57 & $1.01 \times 10^{-3}$ \\
\hline MAD2L1 & 0.57 & $1.01 \times 10^{-3}$ \\
\hline DLK1 & 0.58 & $1.17 \times 10^{-2}$ \\
\hline HDAC2 & 0.58 & $9.39 \times 10^{-5}$ \\
\hline ASCL1 & 0.60 & $3.29 \times 10^{-3}$ \\
\hline SOX4 & 0.60 & $1.89 \times 10^{-2}$ \\
\hline $\mathrm{COCH}$ & 0.60 & $4.20 \times 10^{-4}$ \\
\hline PRDX2 & 0.61 & $7.76 \times 10^{-5}$ \\
\hline FANCA & 0.62 & $4.21 \times 10^{-4}$ \\
\hline RFC5 & 0.62 & $1.00 \times 10^{-5}$ \\
\hline ITGB3BP & 0.63 & $1.14 \times 10^{-3}$ \\
\hline LHX2 & 0.64 & $8.68 \times 10^{-4}$ \\
\hline MCM6 & 0.64 & $5.32 \times 10^{-5}$ \\
\hline CKS2 & 0.65 & $1.92 \times 10^{-3}$ \\
\hline CCNE2 & 0.66 & $2.14 \times 10^{-4}$ \\
\hline ASNS & 0.68 & $5.25 \times 10^{-5}$ \\
\hline CKS1B & 0.69 & $1.55 \times 10^{-3}$ \\
\hline FBXO5 & 0.69 & $9.25 \times 10^{-5}$ \\
\hline $\mathrm{KCNH} 2$ & 0.71 & $2.95 \times 10^{-3}$ \\
\hline TPD52 & 0.75 & $1.99 \times 10^{-4}$ \\
\hline STMN1 & 0.75 & $2.13 \times 10^{-5}$ \\
\hline TYMS & 0.75 & $2.13 \times 10^{-5}$ \\
\hline RRM2 & 0.76 & $6.99 \times 10^{-5}$ \\
\hline CBX5 & 0.76 & $2.44 \times 10^{-3}$ \\
\hline KIF11 & 0.76 & $1.09 \times 10^{-3}$ \\
\hline SOX11 & 0.77 & $1.42 \times 10^{-2}$ \\
\hline RECQL4 & 0.79 & $3.77 \times 10^{-4}$ \\
\hline PCNA & 0.79 & $4.39 \times 10^{-4}$ \\
\hline GMNN & 0.80 & $1.27 \times 10^{-5}$ \\
\hline MYBL2 & 0.81 & $7.84 \times 10^{-4}$ \\
\hline TTK & 0.83 & $5.23 \times 10^{-5}$ \\
\hline TOP2A & 0.84 & $1.95 \times 10^{-4}$ \\
\hline $\mathrm{EZH} 2$ & 0.85 & $7.70 \times 10^{-6}$ \\
\hline PAFAH1B3 & 0.85 & $7.70 \times 10^{-6}$ \\
\hline RAD54L & 0.85 & $7.70 \times 10^{-6}$ \\
\hline TIMELESS & 0.85 & $2.82 \times 10^{-5}$ \\
\hline GNG4 & 0.87 & $1.04 \times 10^{-5}$ \\
\hline SPAG5 & 0.87 & $1.04 \times 10^{-5}$ \\
\hline PTTG1 & 0.88 & $3.01 \times 10^{-5}$ \\
\hline NELL1 & 0.92 & $3.40 \times 10^{-3}$ \\
\hline MEST & 0.93 & $1.25 \times 10^{-3}$ \\
\hline NOL4 & 0.93 & $2.14 \times 10^{-3}$ \\
\hline UCHL1 & 0.94 & $3.18 \times 10^{-3}$ \\
\hline INSM1 & 0.97 & $2.25 \times 10^{-4}$ \\
\hline MKI67 & 0.98 & $1.13 \times 10^{-3}$ \\
\hline PCSK1 & 0.98 & $1.20 \times 10^{-2}$ \\
\hline BIRC5 & 1.00 & $3.28 \times 10^{-5}$ \\
\hline RFC4 & 1.01 & $9.53 \times 10^{-6}$ \\
\hline
\end{tabular}

Table II. Continued.

B, Upregulated DEGs

\begin{tabular}{lcc}
\hline Gene symbol & Log fold-change & Adjusted P-value \\
\hline NEK2 & 1.01 & $9.94 \times 10^{-4}$ \\
CENPF & 1.08 & $1.84 \times 10^{-4}$ \\
CAMK2B & 1.10 & $1.89 \times 10^{-4}$ \\
ISL1 & 1.30 & $7.31 \times 10^{-3}$ \\
GRP & 1.32 & $1.16 \times 10^{-2}$ \\
\hline
\end{tabular}

DEG, differentially expressed genes.

$>10$ were identified. The most significant 10 node degree genes were topoisomerase II $\alpha$ (TOP2A), proliferating cell nuclear antigen (PCNA), replication factor C subunit 4 (RFC4), checkpoint kinase 1 (CHEK1), thymidylate synthase (TYMS), minichromosome maintenance protein (MCM) 2, cell division cycle (CDC) 20, cyclin dependent kinase inhibitor 3 (CDKN3), MCM3 and CDC6. The heat map of the most significant hub genes expression in GSE11969 is shown in Fig. 3B. To assess the basic properties of the PPI network, the Network Analyzer was used to compute several indices, including average clustering coefficient distribution, closeness centrality, average neighborhood connectivity, node degree distribution, shortest path length distribution and topological coefficients. In scale-free networks, the majority of nodes have a low degree, increasing the likely accuracy of the network (30). The computed parameters revealed that the constructed network was scale-free and stable (Fig. 4). In addition, one significant module was obtained from the PPI network of DEGs using MCODE, consisting of 35 nodes and 550 edges (Fig. 3C). Functional and KEGG pathway enrichment analysis revealed that genes in this module were primarily associated with 'cell cycle', 'DNA replication' and 'oocyte meiosis' signaling pathways (Table IV).

Validation of hub genes mRNA level in the oncomine database. Based on the Oncomine database, it was identified that the mRNA expression levels of TOP2A, PCNA, RFC4, CHEK1, TYMS, CDC20, CDKN3, MCM3 and CDC6 were significantly increased in SCLC samples compared with normal lung samples, while MCM2 was not significantly differentially expressed, which was inconsistent with the bioinformatics investigation (Fig. 5).

\section{Discussion}

Although research on SCLC has made great progress in the past decade $(31,32)$, the pathogenesis of SCLC has yet to be fully elucidated due to its complexity of biological traits and high heterogeneity. As a result, the early diagnosis and treatment of SCLC remains a problem. Therefore, understanding of molecular mechanisms of SCLC based on microarray technology, which has developed rapidly and has been widely used to reveal the general genetic alteration in progression of diseases (16-18), may aid the identification of the key gene 

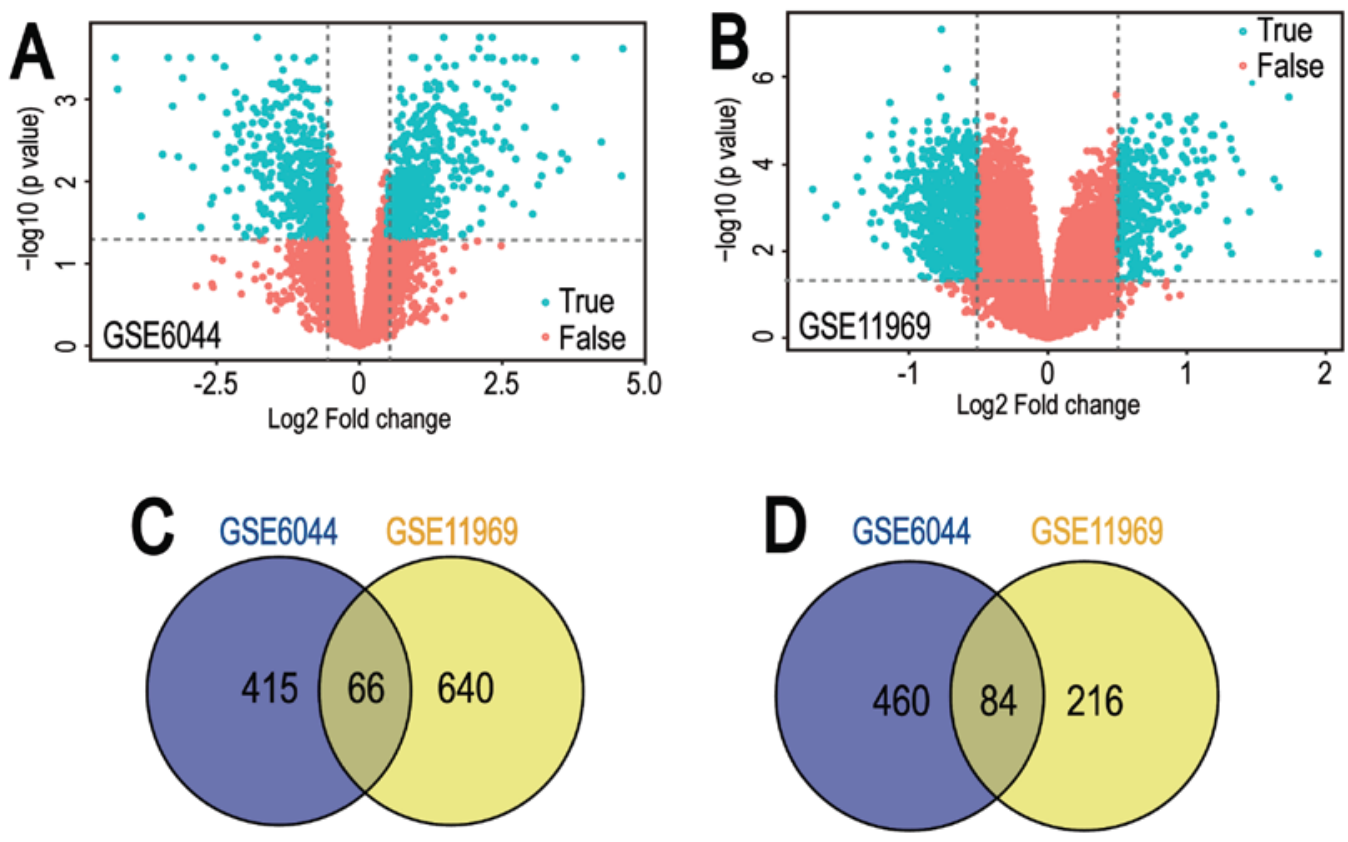

Figure 1. Volcano plot and Venn diagram of DEGs in mRNA expression profiling datasets. Volcano plots of DEGs in normal lung and small cell lung cancer samples in (A) GSE6044 and (B) GSE11969 datasets. DEGs were selected by $\mathrm{P}<0.05$ and $\mid \log _{2}$ (fold-change) $>0.5$. The $x$-axis shows the fold-change in gene expression between normal lung and small cell lung cancer samples, and the y-axis shows the statistical significance of the differences. Colors represent different genes: Red for genes without significantly different expression and blue for significantly differentially expressed genes. Venn diagrams illustrating the number of (C) downregulated and (D) upregulated genes in the two datasets, respectively. The intersection in grey represents the DEGs common between the two datasets. DEG, differentially expressed genes.
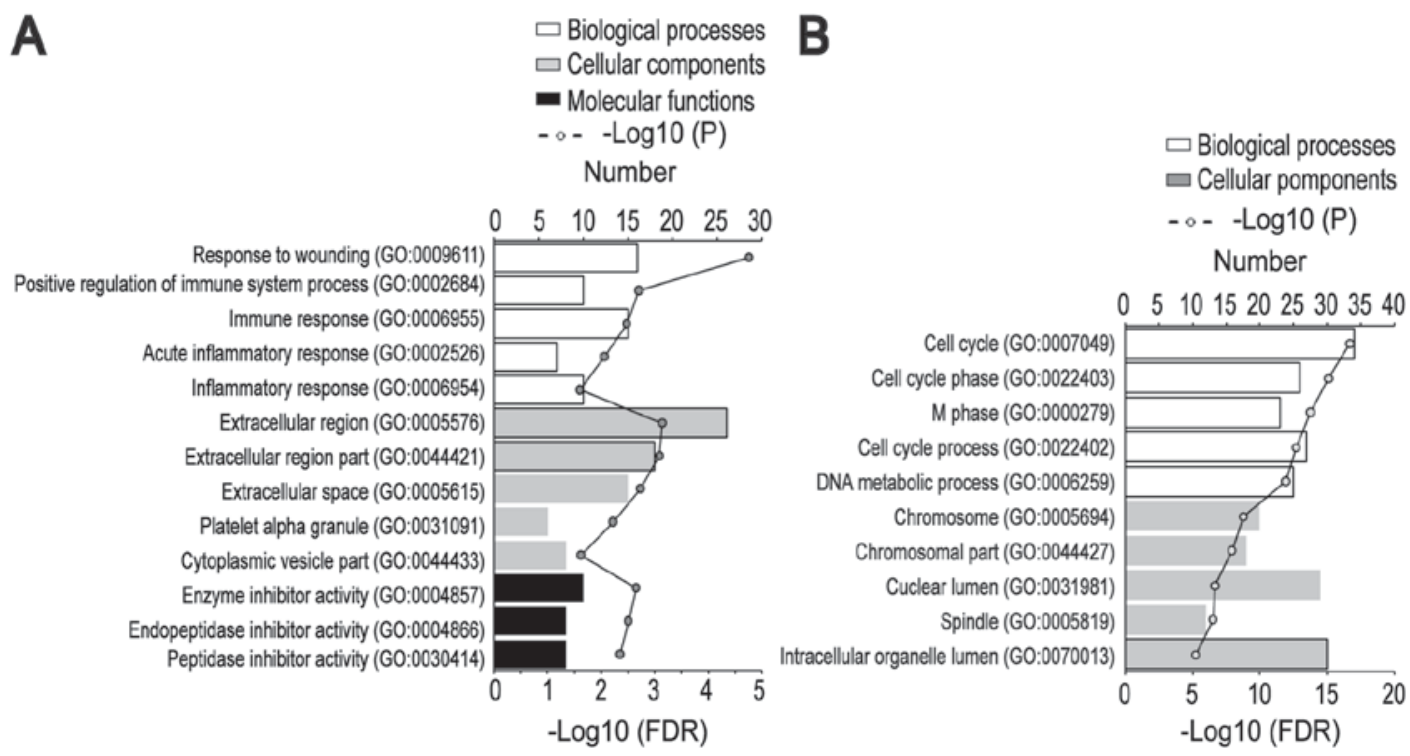

Figure 2. GO classification of common DEGs in the listed categories (top 5 biological processes and cellular components, and top 3 molecular functions). GO enrichment analysis results of (A) downregulated and (B) upregulated common DEGs with $\mathrm{P}<0.05$ and absolute fold-changes $>0.5$. The top $\mathrm{x}$ axis represents the number of genes in the marked category; the bottom $x$ axis indicates the minus $\log _{10}$ (FDR) of categories. Only functional categories with P-value $<0.05$ are shown. GO, Gene Ontology; DEG, differentially expressed genes; FDR, false discovery rate.

targets or signaling pathways for diagnosis, treatment, and prognosis of SCLC.

In the present study, two microarray datasets were obtained to identify the DEGs common to normal lung tissues and SCLC samples. A total of 150 common DEGs, including 66 significantly downregulated DEGs and 84 upregulated DEGs were identified and used for further analysis. To interpret the biological functions of these common DEGs, GO and pathway analysis based on the DAVID tool was performed. GO and pathway analysis for the common DEGs indicated that the common upregulated DEGs were mainly enriched in cell cycle, cell cycle phase, $M$ phase, cell cycle process and DNA metabolic process, and the common downregulated genes were significantly enriched in response to wounding, positive regulation of immune system process, immune response, acute inflammatory response and inflammatory response. These 
A

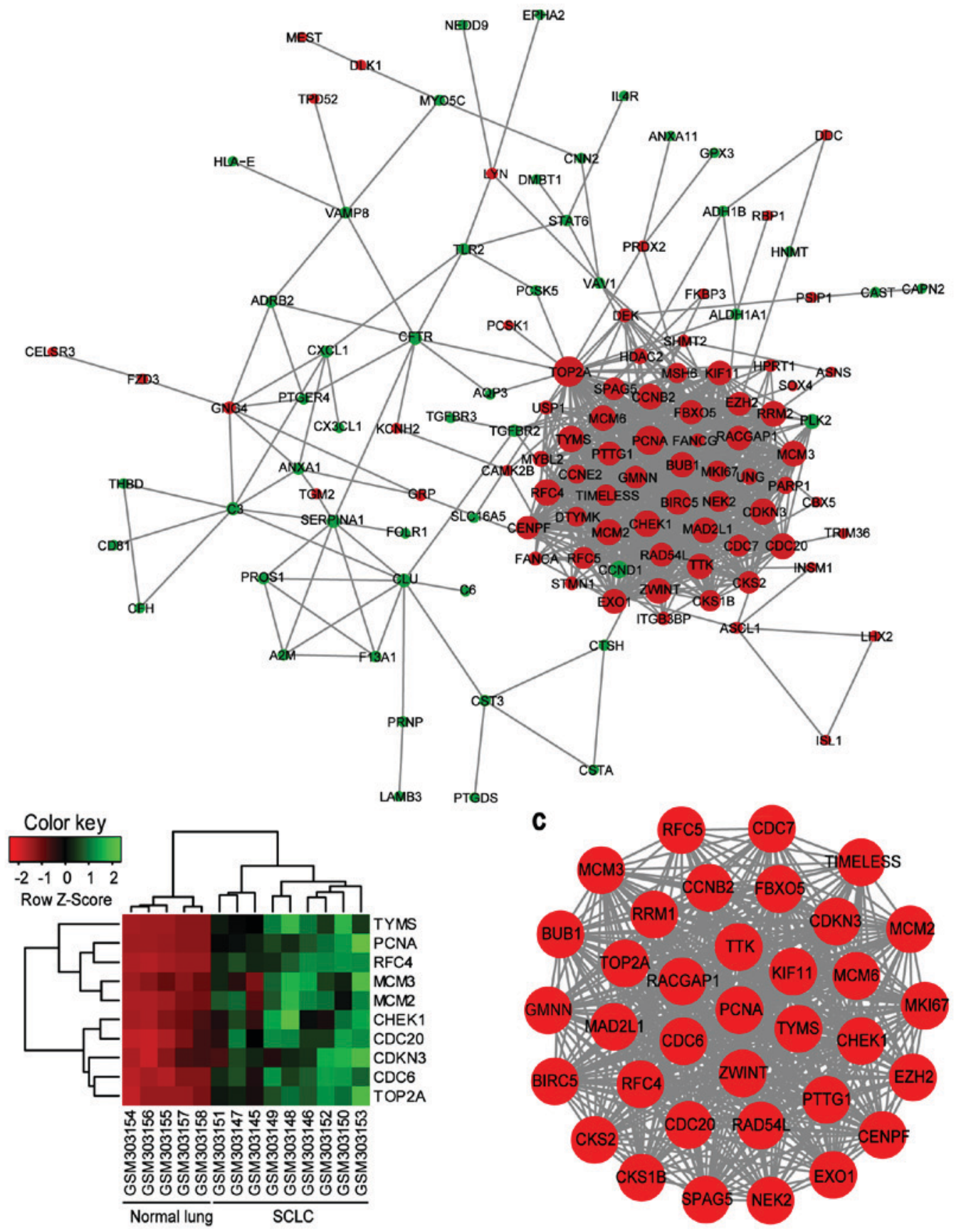

Figure 3. PPI network constructed from the common DEGs, module analysis and hub genes. (A) Using the STRING online database, a total of 123 DEGs were filtered into the DEGs PPI network complex. The nodes represent proteins, the edges represent the interaction of proteins and green circles and red circles indicate downregulated and upregulated DEGs, respectively. (B) Expression heat map of the top 10 hub genes in GSE11969. (C) The most significant module in the PPI network with MCODE score $\geq 4$ and node $>5$. PPI, protein-protein interaction; DEG, differentially expressed genes; MCODE, Molecular Complex Detection plug in; SCLC, small cell lung cancer; TYMS, thymidylate synthase; PCNA, proliferating cell nuclear antigen; RFC4, replication factor C subunit 4; MCM, minichromosome maintenance protein; CHEK1, checkpoint kinase 1; CDC, cell division cycle; CDKN3, cyclin dependent kinase inhibitor 3; TOP2A, topoisomerase II $\alpha$.

results are consistent with the evidence that disorders in cell cycle regulation and alterations of immune response contribute to carcinogenesis and development of tumor (33-35). KEGG pathway analysis indicated that the common downregulated DEGs were mainly enriched in the complement and coagulation cascades signaling pathways. Previous studies have shown that the tissue factor-activated coagulation cascade in the tumor microenvironment, in addition to coagulation, can facilitate the spreading of tumor cell in the pulmonary vasculature during early metastatic colony formation $(36,37)$. Conversely, the common upregulated DEGs were mainly enriched in cell cycle, DNA replication, oocyte meiosis and mismatch repair signaling pathway, consistent with the results from GO and pathway analysis.

To predict the associations of protein functions of the identified 110 common interacting genes, a PPI network was constructed in which the top 10 hub genes with the highest connective degree were selected, including TOP2A, PCNA, RFC4, CHEK1, TYMS, MCM2, CDC20, CDKN3, MCM3 and CDC6, which were also primarily associated with 'cell cycle', 
Table III. Signaling pathway enrichment analysis of common DEGs in normal lung and small cell lung cancer.

\begin{tabular}{|c|c|c|c|c|}
\hline Pathway & Name & Gene count & Genes & FDR \\
\hline \multicolumn{5}{|l|}{ Common downregulated DEGs } \\
\hline KEGG_PATHWAY: hsa04610 & $\begin{array}{l}\text { Complement } \\
\text { and coagulation } \\
\text { cascades }\end{array}$ & 8 & $\begin{array}{l}\text { A2M, THBD, C3, C6, F13A1, CFH, } \\
\text { SERPINA1, PROS1 }\end{array}$ & $3.17 \times 10^{-4}$ \\
\hline \multicolumn{5}{|l|}{ Common upregulated DEGs } \\
\hline KEGG_PATHWAY: hsa04110 & Cell cycle & 15 & $\begin{array}{l}\text { CDC7, CDC6, TTK, CHEK1, CDC20, } \\
\text { PTTG1, MCM2, MCM3, MCM6, CCNE2, } \\
\text { CCNB2, HDAC2, MAD2L1, PCNA, BUB1 }\end{array}$ & $5.06 \times 10^{-11}$ \\
\hline KEGG_PATHWAY: hsa03030 & DNA replication & 6 & RFC5, RFC4, PCNA, MCM2, MCM3, MCM6 & $4.67 \times 10^{-3}$ \\
\hline KEGG_PATHWAY: hsa04114 & Oocyte meiosis & 8 & $\begin{array}{l}\text { CCNE2, MAD2L1, CCNB2, BUB1, FBXO5, } \\
\text { CDC20, CAMK2B, PTTG1 }\end{array}$ & $1.04 \times 10^{-4}$ \\
\hline KEGG_PATHWAY: hsa03430 & Mismatch repair & 5 & RFC5, EXO1, MSH6, RFC4, PCNA & $1.80 \times 10^{-2}$ \\
\hline
\end{tabular}

DEG, differentially expressed genes; FDR, false discovery rate; KEGG, kyoto encyclopedia of genes and genomes.
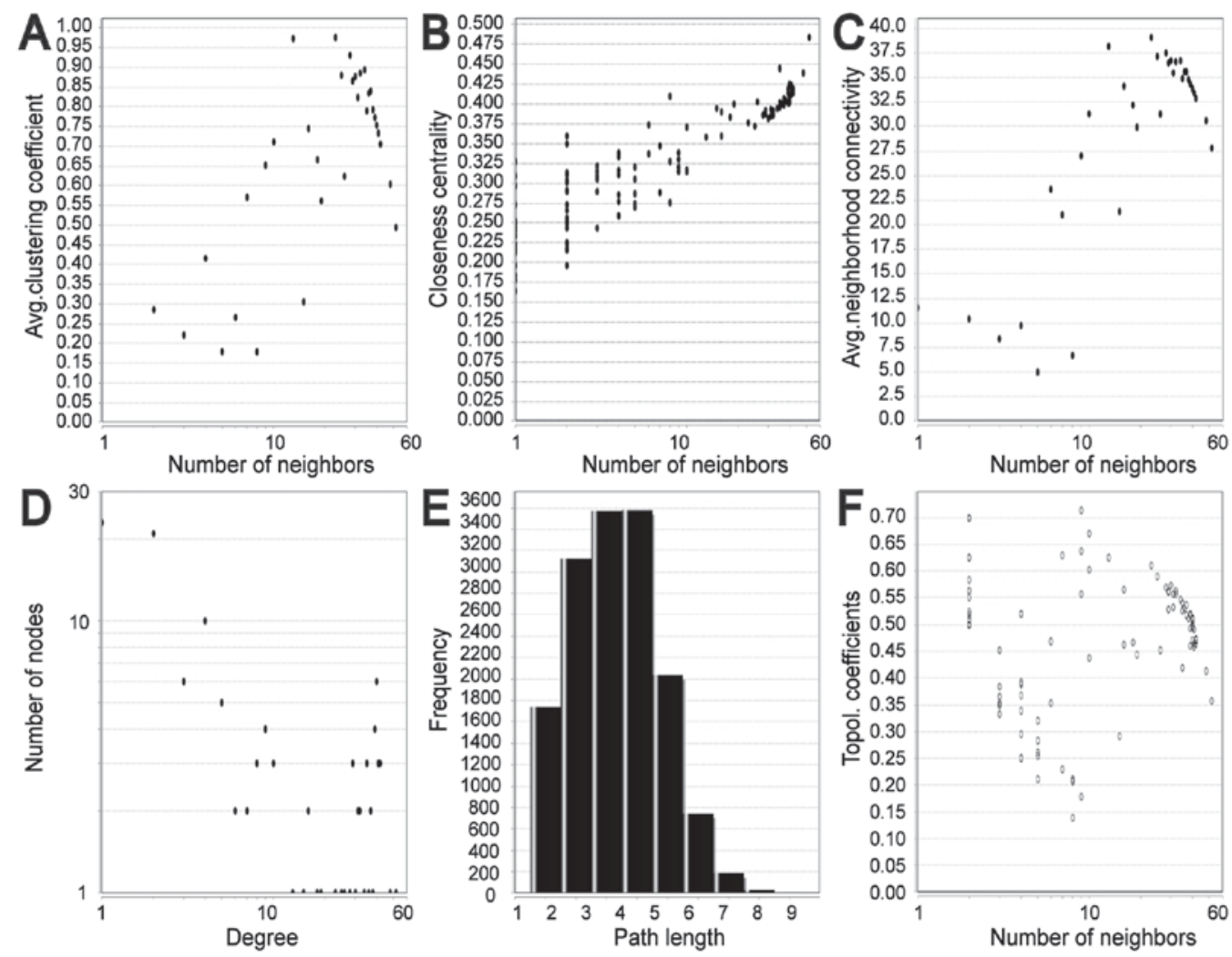

Figure 4. Topological parameters of the protein-protein interaction network. (A) Average clustering coefficient distribution. (B) Closeness centrality. (C) Average neighborhood connectivity distribution. (D) Node-degree distribution. (E) Shortest path length distribution. (F) Topological coefficients. Avg, average; topol, topological.

'DNA replication' and 'oocyte meiosis' signaling pathways. In addition, to validate the expression levels of these hub genes, the mRNA expression level of hub genes was searched for by mining the Oncomine database, which further supported the bioinformatics data. Although previous research has suggested that the majority of these deregulated hub genes correlated with diagnosis, treatment and prognosis of the various malignancies, the precise roles and molecular mechanism of them in the occurrence and development of SCLC have not yet been fully elucidated.

The TOP2A gene encodes a $170 \mathrm{kDa}$ nuclear enzyme that catalyzes the ATP-dependent transport of one intact DNA double helix through another, by which TOP2A is involved in the chromosome segregation and cell cycle progression (38), and numerous studies indicated that the expression, genetic alteration and enzyme activity of TOP2A have been identified 
Table IV. GO function enrichment analysis of gene in module.

\begin{tabular}{|c|c|c|c|c|c|}
\hline Category & Term & Description & Count & Genes & FDR \\
\hline KEGG & hsa04110 & Cell cycle & 13 & $\begin{array}{l}\text { CDC7, CDC6, TTK, CDC20, CHEK1, PTTG1, MCM2, } \\
\text { MCM3, MCM6, CCNB2, MAD2L1, PCNA, BUB1 }\end{array}$ & $5.06 \times 10^{-12}$ \\
\hline KEGG & hsa03030 & DNA replication & 6 & RFC5, RFC4, PCNA, MCM2, MCM3, MCM6 & $1.81 \times 10^{-4}$ \\
\hline KEGG & hsa04114 & Oocyte meiosis & 6 & CCNB2, MAD2L1, BUB1, FBXO5, CDC20, PTTG1 & $4.83 \times 10^{-2}$ \\
\hline
\end{tabular}

GO, Gene Ontology; FDR, false discovery rate; KEGG, kyoto encyclopedia of genes and genomes; Count, the number of enriched genes in each term.
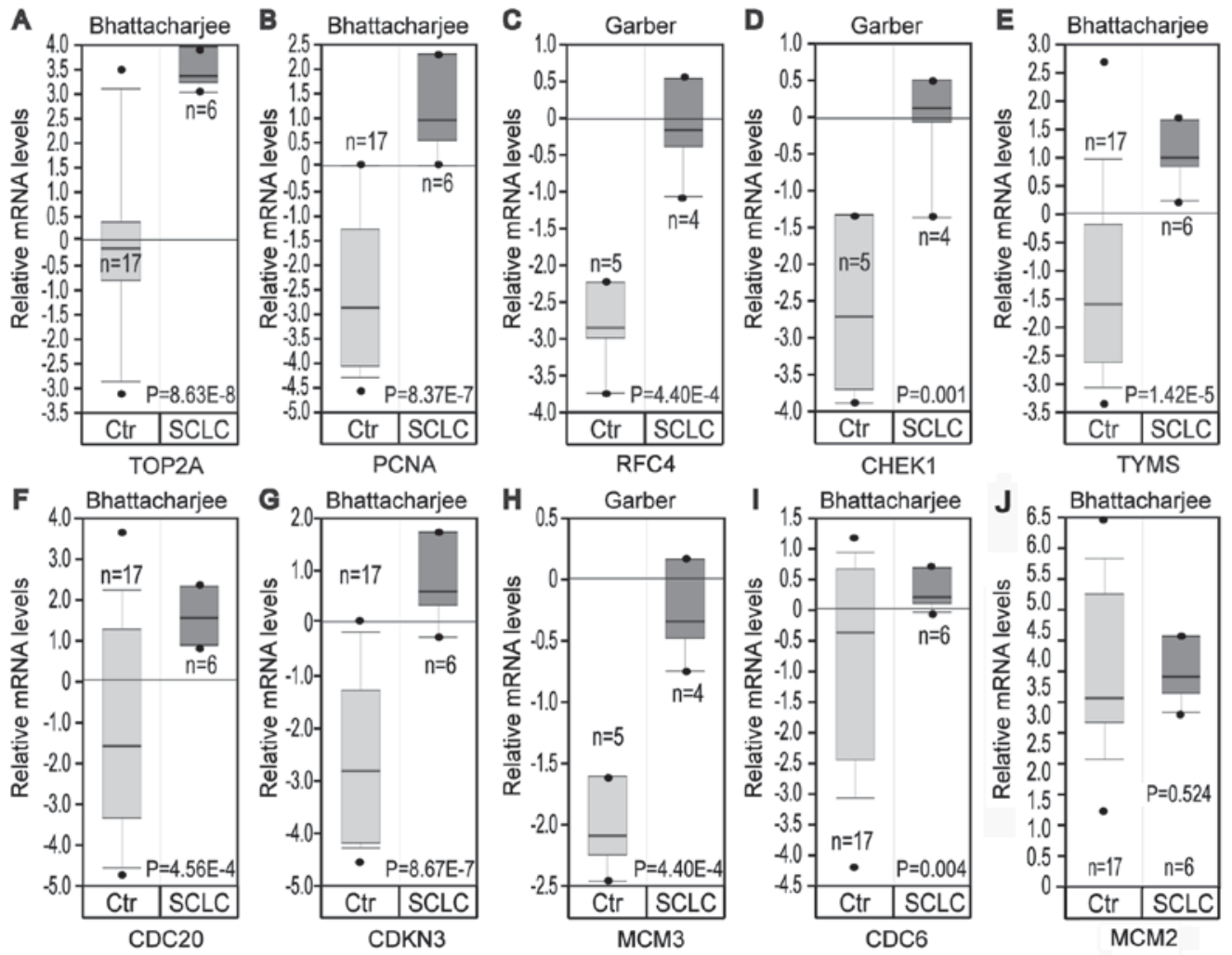

Figure 5. Analysis of expression of hub genes in the Oncomine database. Gene expression data was obtained from Garber and Bhattacharjee lung datasets and analyzed with Oncomine. mRNA expression levels of (A) TOP2A, (B) PCNA, (C) RFC4, (D) CHEK1, (E) TYMS, (F) CDC20, (G) CDKN3, (H) MCM3, (I) CDC6 and (J) MCM2 in normal lung vs. SCLC were compared. Pre-processed expression levels are Log 2 normalized and median centered. Data are presented as box plot with minimum (from bottom to top), 10th percentile, 25 th percentile, median, 75 th percentile, 90 th percentile and maximum. Ctr, control; TOP2A, topoisomerase II $\alpha$; PCNA, proliferating cell nuclear antigen; RFC4, replication factor C subunit 4; CHEK1, checkpoint kinase 1; TYMS, thymidylate synthase; CDC, cell division cycle; CDKN3, cyclin dependent kinase inhibitor 3; MCM, minichromosome maintenance protein; SCLC, small cell lung cancer.

in several types of malignancies; therefore, it TOP $2 A$ should be investigated to determine whether it represents an effective therapeutic target for a wide variety of malignancies, such as SCLC, testicular cancer, neuroblastoma, leukemia and lymphoma (39-41).

PCNA encodes a nuclear protein acting as a subunit of DNA polymerase $\delta$, which is essential for DNA replication (42). Although several studies have been performed to investigate the association between PCNA expression and clinical properties of NSCLC, the data is controversial; certain studies claimed that patients with increased expression of PCNA had a worse outcome compared with patients with a lower expression of PCNA (43-45), however, a subsequent study indicated that PCNA cannot predict disease-free survival in patients with lung adenocarcinoma (46). Furthermore, no correlation has been observed between PCNA expression in biopsy specimens and tumor responsiveness to chemotherapy (47).

RFC4 encodes the fourth largest subunit of the RFC complex, which helps PCNA load onto DNA in an ATP-dependent process during DNA synthesis and serves an important role in DNA repair activities following DNA damage. It has been reported that the expression level of RFC4 is upregulated in colorectal cancer, correlates with tumor progression and can predict the prognosis for colorectal cancer (48).

CHEK1 is an evolutionarily conserved Ser/Thr kinase, which mediates cell-cycle arrest following DNA damage (49). Previous results demonstrated that upregulated CHEK1 has been considered a potential target for cancer therapy $(50,51)$. 
Therefore, CHEK1 inhibitors (including LY2606368) have been tested as treatment for several types of cancer including lung cancer, and the inhibitors may affect the sensitivity of radiotherapy and chemotherapy, including cisplatin or the PARP inhibitor olaparib (52-55).

TYMS is a key enzyme in the de novo synthesis of thymidine and is upregulated in different histological types of lung cancer, particularly in SCLC (56). In addition, the expression level of TYMS is considered to be associated with the prognosis and treatment efficacy of chemotherapy $(57,58)$.

MCM2 is a component of the prereplicative complex, which is essential for eukaryotic DNA replication and is only expressed in proliferating cells. Several studies indicated that the expression of MCM2 is also upregulated in NSCLC and is a predictor of survival in patients with NSCLC (59). Recently, Cheung et al (60) performed a multi-dimensional proteomic analysis to investigate the biological networks of MCM2 in the lung cancer and the results indicated that the deregulation of MCM2 is involved in lung cancer cell proliferation, the cell cycle and migration.

MCM3, another family member of MCMs, has been proved to be overexpressed in various human cancers, including leukemia, malignant melanoma, lymphoma, and carcinomas of the uterine cervix, colon, lung, stomach, kidney and breast (61).

CDC20, a homolog of Saccharomyces cerevisiae cell division cycle 20 protein, is an activator for the anaphase-promoting complex. Evidence has demonstrated that CDC20 is essential to govern cell cycle progression for cell division by targeting several key substrates including securin, cyclin B1, cyclin A, Nek2A, p21 and myeloid cell leukemia-1 for degradation $(62,63)$. Subsequent studies have indicated that CDC20 is frequently upregulated in numerous types of malignancies, including NSCLC, and is associated with the prognosis of patients with tumors $(64,65)$.

CDKN3 is a negative regulator of CDK1 and CDK2 (66). Since CDK-driven cell cycle is essential for proliferation of cancer cells and CDKN3 inhibits CDK activities, CDKN3 was initially perceived as a tumor suppressor (66). However, the overexpression of CNKN3 in a number of types of cancers has recently demonstrated that CDKN3 mRNA overexpression in cancer is due to the presence of dominant-negative CDKN3 mutations $(67,68)$. Although upregulated CDKN3 may be a prognostic marker in lung adenocarcinoma and serve functional roles in the pathogenesis and diagnosis of SCLC, it has not been investigated other aggressive forms of lung tumors (69).

CDC6, initially identified to participate in the assembly of pre-replication complexes, is essential for DNA replication in mammalian cells (70). CDC6 expression represses E-cadherin transcription, and loss of this gene occurs frequently in carcinogenesis, contributing to invasion and metastasis (71). In addition, previous studies have confirmed the association between CDC6 and prognosis and the treatment sensitivity of patients with tumors $(72,73)$.

Therefore, given the key roles, associated signaling pathways and results of the present study on the hub genes mentioned above, future studies may focus on these to explore their roles in the pathogenesis and diagnosis of SCLC. However, the present study has certain limitations: One is that the microarray data were obtained from GEO database, not generated by the authors. Another limitation of the study is the relatively small sample size.

In summary, based on the gene expression profile analysis of microarray datasets, the present study identified the common deregulated DEGs between normal lung tissues and SCLC tissues, associated signaling pathways and hub genes in the network in different datasets, which may possess important roles in the carcinogenesis and development of SCLC. These findings may provide new clues for the investigation of the potential biomarkers and biological mechanisms of SCLC, further developing the potential diagnosis and therapeutic intervention methods of SCLC.

\section{Acknowledgements}

Not applicable.

\section{Funding}

The present study was supported by the National Natural Science Foundation of China (grant no. 81501959), Doctoral Scientific Research Starting Foundation of Liaoning Province (grant no. 2015010911-301), Technological Project of Liaoning Province (grant no. 20170540392), Innovation Foundation for the University Students (grant no. 201510160000013) and Biological Anthropology Innovation Team Project of JZMU (grant no. JYLJ201702).

\section{Availability of data and materials}

The datasets used and/or analyzed in the present study are available from the corresponding authors on reasonable request.

\section{Authors' contributions}

YL and JG designed the study. PW, TC, ZS and TW analyzed the microarray datasets and interpreted the results. HG and NW downloaded the gene expression profile from the Gene Expression Omnibus. TC and TW wrote and edited the manuscript. All authors critically reviewed the content and approved the final version for publication.

\section{Ethics approval and consent to participate}

Not applicable.

\section{Consent for publication}

Not applicable.

\section{Competing interests}

The authors declare that they have no competing interests.

\section{References}

1. Chen W, Zheng R, Baade PD, Zhang S, Zeng H, Bray F, Jemal A, Yu XQ and He J: Cancer statistics in China, 2015. CA Cancer J Clin 66: 115-132, 2016. 
2. Ferlay J, Shin HR, Bray F, Forman D, Mathers C and Parkin DM: Estimates of worldwide burden of cancer in 2008: GLOBOCAN 2008. Int J Cancer 127: 2893-2917, 2010.

3. Luchtenborg M, Riaz SP, Lim E, Page R, Baldwin DR, Jakobsen E, Vedsted P, Lind M, Peake MD, Mellemgaard A, et al: Survival of patients with small cell lung cancer undergoing lung resection in England, 1998-2009. Thorax 69: 269-273, 2014.

4. Sabari JK, Lok BH, Laird JH, Poirier JT and Rudin CM: Unravelling the biology of SCLC: Implications for therapy. Nat Rev Clin Oncol 14: 549-561, 2017.

5. Nicholson AG, Chansky K, Crowley J, Beyruti R, Kubota K, Turrisi A, Eberhardt WE, van Meerbeeck J and Rami-Porta R Staging and Prognostic Factors Committee, Advisory Boards, and Participating Institutions; Staging and Prognostic Factors Committee Advisory Boards and Participating Institutions: The international association for the study of lung cancer lung cancer staging project: Proposals for the revision of the clinical and pathologic staging of small cell lung cancer in the forthcoming eighth edition of the TNM classification for lung cancer. J Thorac Oncol 11: 300-311, 2016.

6. George J, Lim JS, Jang SJ, Cun Y, Ozretić L, Kong G, Leenders F, Lu X, Fernández-Cuesta L, Bosco G, Müller C, et al: Comprehensive genomic profiles of small cell lung cancer. Nature 524: 47-53, 2015.

7. Mori N, Yokota J, Akiyama T, Sameshima Y, Okamoto A, Mizoguchi H, Toyoshima K, Sugimura T and Terada M: Variable mutations of the RB gene in small-cell lung carcinoma Oncogene 5: 1713-1717, 1990

8. Rudin CM, Durinck S, Stawiski EW, Poirier JT, Modrusan Z, Shames DS, Bergbower EA, Guan Y, Shin J, Guillory J, et al: Comprehensive genomic analysis identifies SOX2 as a frequently amplified gene in small-cell lung cancer. Nat Genet 44: 1111-1116, 2012.

9. Brambilla E, Negoescu A, Gazzeri S, Lantuejoul S, Moro D, Brambilla C and Coll JL: Apoptosis-related factors p53, Bcl2, and Bax in neuroendocrine lung tumors. Am J Pathol 149 : 1941-1952, 1996.

10. Arriola E, Canadas I, Arumi M, Rojo F, Rovira A and Albanell J: Genetic changes in small cell lung carcinoma. Clin Transl Oncol 10: 189-197, 2008

11. de Bono J, Ramanathan RK, Mina L, Chugh R, Glaspy J, Rafii S, Kaye S, Sachdev J, Heymach J, Smith DC, et al: Phase I, Dose-escalation, Two-Part trial of the PARP inhibitor talazoparib in patients with advanced germline BRCA1/2 mutations and selected sporadic cancers. Cancer Discov 7: 620-629, 2017.

12. Byers LA, Wang J, Nilsson MB, Fujimoto J, Saintigny P, Yordy J, Giri U, Peyton M, Fan YH, Diao L, et al: Proteomic profiling identifies dysregulated pathways in small cell lung cancer and novel therapeutic targets including PARP1. Cancer Discov 2: 798-811, 2012

13. Borromeo MD, Savage TK, Kollipara RK, He M, Augustyn A, Osborne JK, Girard L, Minna JD, Gazdar AF, Cobb MH and Johnson JE: ASCL1 and NEUROD1 reveal heterogeneity in pulmonary neuroendocrine tumors and regulate distinct genetic programs. Cell Rep 16: 1259-1272, 2016.

14. Gardner EE, Lok BH, Schneeberger VE, Desmeules P, Miles LA, Arnold PK, Ni A, Khodos I, de Stanchina E, Nguyen T, et al: Chemosensitive relapse in small cell lung cancer proceeds through an EZH2-SLFN11 Axis. Cancer Cell 31: 286-299, 2017.

15. Hirai H, Iwasawa Y, Okada M, Arai T, Nishibata T, Kobayashi M, Kimura T, Kaneko N, Ohtani J, Yamanaka K, et al: Small-molecule inhibition of Weel kinase by MK-1775 selectively sensitizes p53-deficient tumor cells to DNA-damaging agents. Mol Cancer Ther 8: 2992-3000, 2009.

16. Albertson DG and Pinkel D: Genomic microarrays in human genetic disease and cancer. Hum Mol Genet 12: R145-R152, 2003.

17. Singhal S, Miller D, Ramalingam S and Sun SY: Gene expression profiling of non-small cell lung cancer. Lung Cancer 60: 313-324, 2008.

18. Al Zeyadi M, Dimova I, Ranchich V, Rukova B, Nesheva D, Hamude Z, Georgiev S, Petrov D and Toncheva D: Whole genome microarray analysis in non-small cell lung cancer. Biotechnol Biotechnol Equip 29: 111-118, 2015.

19. Kikuchi T, Daigo Y, Katagiri T, Tsunoda T, Okada K, Kakiuchi S, Zembutsu H, Furukawa Y, Kawamura M, Kobayashi K, et al: Expression profiles of non-small cell lung cancers on cDNA microarrays: Identification of genes for prediction of lymph-node metastasis and sensitivity to anti-cancer drugs. Oncogene 22 : 2192-2205, 2003.
20. Yanaihara N, Caplen N, Bowman E, Seike M, Kumamoto K, Yi M, Stephens RM, Okamoto A, Yokota J, Tanaka T, et al: Unique microRNA molecular profiles in lung cancer diagnosis and prognosis. Cancer Cell 9: 189-198, 2006

21. Bhattacharjee A, Richards WG, Staunton J, Li C, Monti S, Vasa P, Ladd C, Beheshti J, Bueno R, Gillette M, et al: Classification of human lung carcinomas by mRNA expression profiling reveals distinct adenocarcinoma subclasses. Proc Natl Acad Sci USA 98: 13790-13795, 2001.

22. Edgar R, Domrachev M and Lash AE: Gene expression omnibus: NCBI gene expression and hybridization array data repository. Nucleic Acids Res 30: 207-210, 2002.

23. Rohrbeck A, Neukirchen J, Rosskopf M, Pardillos GG, Geddert H, Schwalen A, Gabbert HE, von Haeseler A, Pitschke G, Schott M, et al: Gene expression profiling for molecular distinction and characterization of laser captured primary lung cancers. J Transl Med 6: 69, 2008.

24. Takeuchi T, Tomida S, Yatabe Y, Kosaka T, Osada H, Yanagisawa K, Mitsudomi $\mathrm{T}$ and Takahashi T: Expression profile-defined classification of lung adenocarcinoma shows close relationship with underlying major genetic changes and clinicopathologic behaviors. J Clin Oncol 24: 1679-1688, 2006.

25. Barrett T, Wilhite SE, Ledoux P, Evangelista C, Kim IF, Tomashevsky M, Marshall KA, Phillippy KH, Sherman PM, Holko M, et al: NCBI GEO: Archive for functional genomics data sets-update. Nucleic Acids Res 41 (Database Issue): D991-D995, 2013.

26. Huang da W, Sherman BT and Lempicki RA: Systematic and integrative analysis of large gene lists using DAVID bioinformatics resources. Nat Protoc 4: 44-57, 2009.

27. Assenov Y, Ramírez F, Schelhorn SE, Lengauer $T$ and Albrecht M: Computing topological parameters of biological networks. Bioinformatics 24: 282-284, 2008.

28. Rhodes DR, Kalyana-Sundaram S, Mahavisno V, Varambally R, Yu J, Briggs BB, Barrette TR, Anstet MJ, Kincead-Beal C, Kulkarni P, et al: Oncomine 3.0: Genes, pathways, and networks in a collection of 18,000 cancer gene expression profiles. Neoplasia 9: 166-180, 2007.

29. Garber ME, Troyanskaya OG, Schluens K, Petersen S, Thaesler Z, Pacyna-Gengelbach M, van de Rijn M, Rosen GD, Perou CM, Whyte RI, et al: Diversity of gene expression in adenocarcinoma of the lung. Proc Natl Acad Sci USA 98: 13784-13789, 2001.

30. DiezD, Wheelock AM, Goto S,Haeggström JZ,Paulsson-Berne G, Hansson GK, Hedin U, Gabrielsen A and Wheelock CE: The use of network analyses for elucidating mechanisms in cardiovascular disease. Mol Biosyst 6: 289-304, 2010.

31. Karachaliou N, Pilotto S, Lazzari C, Bria E, de Marinis F and Rosell R: Cellular and molecular biology of small cell lung cancer: An overview. Transl Lung Cancer Res 5: 2-15, 2016.

32. Pietanza MC, Byers LA, Minna JD and Rudin CM: Small cell lung cancer: Will recent progress lead to improved outcomes? Clin Cancer Res 21: 2244-2255, 2015.

33. Sica A and Bronte V: Altered macrophage differentiation and immune dysfunction in tumor development. J Clin Invest 117 1155-1166, 2007.

34. Mantovani A, Allavena P, Sica A and Balkwill F: Cancer-related inflammation. Nature 454: 436-444, 2008.

35. Reiche EM, Nunes SO and Morimoto HK: Stress, depression, the immune system, and cancer. Lancet Oncol 5: 617-625, 2004.

36. Liu Y, Jiang P, Capkova K, Xue D, Ye L, Sinha SC, Mackman N, Janda KD and Liu C: Tissue factor-activated coagulation cascade in the tumor microenvironment is critical for tumor progression and an effective target for therapy. Cancer Res 71: 6492-6502, 2011.

37. Im JH, Fu W, Wang H, Bhatia SK, Hammer DA, Kowalska MA and Muschel RJ: Coagulation facilitates tumor cell spreading in the pulmonary vasculature during early metastatic colony formation. Cancer Res 64: 8613-8619, 2004.

38. Champoux JJ: DNA topoisomerases: Structure, function, and mechanism. Annu Rev Biochem 70: 369-413, 2001.

39. Chen T, Sun Y, Ji P, Kopetz S and Zhang W: Topoisomerase II $\alpha$ in chromosome instability and personalized cancer therapy. Oncogene 34: 4019-4031, 2015.

40. Jain M, Zhang L, He M, Zhang YQ, Shen M and Kebebew E: TOP2A is overexpressed and is a therapeutic target for adrenocortical carcinoma. Endocr Relat Cancer 20: 361-370, 2013.

41. O'Malley FP, Chia S, Tu D, Shepherd LE, Levine MN, Bramwell VH, Andrulis IL and Pritchard KI: Topoisomerase II Alpha and responsiveness of breast cancer to adjuvant chemotherapy. J Natl Cancer Inst 101: 644-650, 2009. 
42. Maga $G$ and Hubscher U: Proliferating cell nuclear antigen (PCNA): A dancer with many partners. J Cell Sci 116: 3051-3060, 2003.

43. del Giglio A, O'Brien S, Ford R, Saya H, Manning J, Keating M, Johnston D, Khetan R, el-Naggar A and Deisseroth A: Prognostic value of proliferating cell nuclear antigen expression in chronic lymphoid leukemia. Blood 79: 2717-2720, 1992.

44. Kinugasa S, Tachibana M, Hishikawa Y, Abe S, Yoshimura H, Monden N, Dhar DK and Nagasue N: Prognostic significance of proliferating cell nuclear antigen (PCNA) in squamous cell carcinoma of the esophagus. Jpn J Clin Oncol 26: 405-410, 1996.

45. Caputi M, Esposito V, Groger AM, Pacilio C, Murabito M Dekan G, Baldi F, Wolner E and Giordano A: Prognostic role of proliferating cell nuclear antigen in lung cancer: An immunohistochemical analysis. In Vivo 12: 85-88, 1998.

46. Oka S, Uramoto H, Shimokawa H, Iwanami T and Tanaka F: The expression of $\mathrm{Ki}-67$, but not proliferating cell nuclear antigen predicts poor disease free survival in patients with adenocarcinoma of the lung. Anticancer Res 31: 4277-4282, 2011.

47. Zdunek M and Korobowicz E: Expression of PCNA in non-small cell lung cancer before and after treatment with cisplatin and vepeside. Pol J Pathol 51: 77-81, 2000.

48. Xiang J, Fang L, Luo Y, Yang Z, Liao Y, Cui J, Huang M, Yang Z, Huang Y, Fan X, et al: Levels of human replication factor C4, a clamp loader, correlate with tumor progression and predict the prognosis for colorectal cancer. J Transl Med 12: 320, 2014.

49. Dai Y and Grant S: New insights into checkpoint kinase 1 in the DNA damage response signaling network. Clin Cancer Res 16 376-383, 2010

50. DoerrF,George J,SchmittA,BeleggiaF, RehkämperT,HermannS Walter V, Weber JP, Thomas RK, Wittersheim M, et al: Targeting a non-oncogene addiction to the ATR/CHK1 axis for the treatment of small cell lung cancer. Sci Rep 7: 15511, 2017.

51. Garrett MD and Collins I: Anticancer therapy with checkpoint inhibitors: What, where and when? Trends Pharmacol Sci 32 308-316, 2011

52. Xie Y, Wei RR, Huang GL, Zhang MY, Yuan YF and Wang HY: Checkpoint kinase 1 is negatively regulated by miR-497 in hepatocellular carcinoma. Med Oncol 31: 844, 2014.

53. Liu B, Qu J, Xu F, Guo Y, Wang Y, Yu H and Qian B: MiR-195 suppresses non-small cell lung cancer by targeting CHEK1. Oncotarget 6: 9445-9456, 2015.

54. McNeely S, Beckmann R and Bence Lin AK: CHEK again: Revisiting the development of CHK1 inhibitors for cancer therapy. Pharmacol Ther 142: 1-10, 2014.

55. Sen T, Tong P, Stewart CA, Cristea S, Valliani A, Shames DS, Redwood AB, Fan YH, Li L, Glisson BS, et al: CHK1 Inhibition in small-cell lung cancer produces Single-agent activity in Biomarker-defined disease subsets and combination activity with cisplatin or olaparib. Cancer Res 77: 3870-3884, 2017.

56. Tanaka F, Wada H, Fukui Y and Fukushima M: Thymidylate synthase (TS) gene expression in primary lung cancer patients: A large-scale study in Japanese population. Ann Oncol 22: 1791-1797, 2011

57. Chen CY, Chang YL, Shih JY, Lin JW, Chen KY, Yang CH, Yu CJ and Yang PC: Thymidylate synthase and dihydrofolate reductase expression in non-small cell lung carcinoma: The association with treatment efficacy of pemetrexed. Lung Cancer 74 132-138, 2011

58. Chamizo C, Zazo S, Domine M, Cristóbal I, García-Foncillas J, Rojo F and Madoz-Gúrpide J: Thymidylate synthase expression as a predictive biomarker of pemetrexed sensitivity in advanced non-small cell lung cancer. BMC Pulm Med 15: 132, 2015.
59. Ramnath N, Hernandez FJ, Tan DF, Huberman JA, Natarajan N, Beck AF, Hyland A, Todorov IT, Brooks JS and Bepler G: MCM2 is an independent predictor of survival in patients with non-small-cell lung cancer. J Clin Oncol 19: 4259-4266, 2001.

60. Cheung CHY, Hsu CL, Chen KP, Chong ST, Wu CH, Huang HC and Juan HF: MCM2-regulated functional networks in lung cancer by multi-dimensional proteomic approach. Sci Rep 7: 13302, 2017.

61. Ha SA, Shin SM, Namkoong H, Lee H, Cho GW, Hur SY, Kim TE and Kim JW: Cancer-associated expression of minichromosome maintenance 3 gene in several human cancers and its involvement in tumorigenesis. Clin Cancer Res 10: 8386-8395, 2004.

62. Kidokoro T, Tanikawa C, Furukawa Y, Katagiri T, Nakamura Y and Matsuda K: CDC20, a potential cancer therapeutic target, is negatively regulated by $\mathrm{p} 53$. Oncogene 27: 1562-1571, 2008.

63. Wang L, Zhang J, Wan L, Zhou X, Wang Z and Wei W: Targeting Cdc20 as a novel cancer therapeutic strategy. Pharmacol Ther 151: 141-151, 2015

64. Chang DZ, Ma Y, Ji B, Liu Y, Hwu P, Abbruzzese JL, Logsdon C and Wang H: Increased CDC20 expression is associated with pancreatic ductal adenocarcinoma differentiation and progression. J Hematol Oncol 5: 15, 2012.

65. Kato T, Daigo Y, Aragaki M, Ishikawa K, Sato M and Kaji M: Overexpression of CDC20 predicts poor prognosis in primary non-small cell lung cancer patients. J Surg Oncol 106: 423-430, 2012.

66. Fan C, Chen L, Huang Q, Shen T, Welsh EA, Teer JK, Cai J, Cress WD and Wu J: Overexpression of major CDKN3 transcripts is associated with poor survival in lung adenocarcinoma. Br J Cancer 113: 1735-1743, 2015.

67. Yu Y, Jiang X, Schoch BS, Carroll RS, Black PM and Johnson MD: Aberrant splicing of cyclin-dependent kinase-associated protein phosphatase KAP increases proliferation and migration in glioblastoma. Cancer Res 67: 130-138, 2007.

68. Yeh CT, Lu SC, Chen TC, Peng CY and Liaw YF: Aberrant transcripts of the cyclin-dependent kinase-associated protein phosphatase in hepatocellular carcinoma. Cancer Res 60: 4697-4700, 2007

69. Zang X, Chen M, Zhou Y, Xiao G, Xie Y and Wang X: Identifying CDKN3 gene expression as a prognostic biomarker in lung adenocarcinoma via Meta-analysis. Cancer Inform 14 (Suppl 2): S183-S191, 2015.

70. Borlado LR and Méndez J: CDC6: From DNA replication to cell cycle checkpoints and oncogenesis. Carcinogenesis 29: 237-243, 2007.

71. Sideridou M, Zakopoulou R, Evangelou K, Liontos M, Kotsinas A, Rampakakis E, Gagos S, Kahata K, Grabusic K, Gkouskou K, et al: Cdc6 expression represses E-cadherin transcription and activates adjacent replication origins. J Cell Biol 195: 1123-1140, 2011.

72. Zhang X, Xiao D, Wang Z, Zou Y, Huang L, Lin W, Deng Q, Pan H, Zhou J, Liang C and He J: MicroRNA-26a/b regulate DNA replication licensing, tumorigenesis, and prognosis by targeting CDC6 in lung cancer. Mol Cancer Res 12: 1535-1546, 2014.

73. Mahadevappa R, Neves H, Yuen SM, Bai Y, McCrudden CM, Yuen HF, Wen Q, Zhang SD and Kwok HF: The prognostic significance of Cdc6 and Cdt1 in breast cancer. Sci Rep 7: 985, 2017.

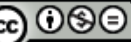

This work is licensed under a Creative Commons Attribution-NonCommercial-NoDerivatives 4.0 International (CC BY-NC-ND 4.0) License. 